\title{
Suppplementary Materials
}

This supplement gives additional model-measurement comparisons, an analysis of the model initialization and the correlation tables for the measurement sites at $150 \mathrm{hPa}, 500$ $\mathrm{hPa}$ and the surface.

Figure S1 shows sensitivity tests to the simulation's initialization. We were initially concerned that the increase in the stratospheric portion of ozone could be attributed to a poor initialization of Synoz*. That is, if the initial simulated concentrations of Synoz* were not in equilibrium, then an increase in the stratospheric portion of ozone could not necessarily be ascribed circulation changes. It might be simply due to an adjustment of Synoz towards equilibrium. To test this hypothesis we ran a number of sensitivity tests. In these sensitivity tests we ran a number of additional simulations of three periods: A) 19881989, B) 1989-1990 and C) 2003-2004. These periods were chosen as representative years towards the beginning of the simulation period when one might expect the simulation to be the most out of equilibrium. In these sensitivity tests we repeated the meteorology from the original simulation year, but allowed the chemistry to evolve; thus, the initial chemical condition for each successive simulation of the same period was taken as the final condition from the previous simulation of that period. We iterated this process four times over period A), 3 times over period B) and 2 times over period C). While Figure S1 suggests the simulation rapidly reaches equilibrium after only one iteration, it is instructive to use multiple iterations for selected periods. If the stratospheric portion of the ozone were increasing because Synoz was out of equilibrium then we would expect that Synoz would continue to increase even if the meteorology were interannually constant. However, the sensitivity tests suggest this is not the case. Generally we found the portion of stratospheric ozone in the troposphere to be rather insensitive to the initial conditions: for each successive simulation over the three periods the ozone concentration on December 31 is almost identical to that in the previous simulation. Thus on the timescale of a year the stratospheric ozone within the troposphere is strongly dependent on the meteorology, and nearly independent of the initial conditions (within the range of initial conditions examined). This is particularly striking for the 1988-1989 period when the stratospheric ozone concentration is clearly out of balance during the initial simulation. However, within a year (i.e., December 31,1988), the stratospheric portion of ozone rapidly equilibrates to a value that appears relatively insensitive to the initial chemical conditions.

Figure S2-S4 gives the simulated and measured: (i) 3-month smoothed monthly mean ozone timeseries (ii) the average ozone seasonal cycle over key measurement regions at $500 \mathrm{hPa}$ (Canada, the Eastern US, Northern Europe and Central Europe). The simulated seasonal cycle generally underestimates the amplitude of the measured cyle. The latter tends to have higher ozone concentrations in summer and lower ozone concentrations in winter. The average simulated ozone maximum is generally one month later than the observed maximum.

Figures S5-S6 give vertical profile of ozone as simulated in the model and measured over key measurement regions (Canada, the Eastern US, Northern Europe and Central Europe). The simulation is generally biased high throughout the troposphere, although above the 
1 boundary layer the bias is not very large. At the surface the bias is more significant. A

2 positive surface bias is common to many global simulations (Pazzoli et al., 2011; Ellingsen

3 et al., 2008). These results are very similar to those given by Hess and Lamarque (2007)

4 using the MOZART-2 chemical transport model. This is notable as the simulation reported

5 in Hess and Lamarque (2007) used Synoz as specified in McLinden et al. (2000).

6 Figures S7 shows simulated and measured ozone at Mace Head.

7 Tables S1 through S3 give correlations between the individual measurement sites examined 8 at $150 \mathrm{hPa}, 500 \mathrm{hPa}$ and the surface. Ozone concentrations in the baseline measurement

9 record, the unfiltered measurement record and model simulation are on average 4.1, 1.9 and $101.0 \mathrm{ppbv}$ higher respectively subsequent to 1999 than prior to 1997 . Eighty percent of the 11 simulated jump in ozone between the period prior to 1997 and subsequent to 1999 is due to 12 increases in the stratospheric component of ozone. 


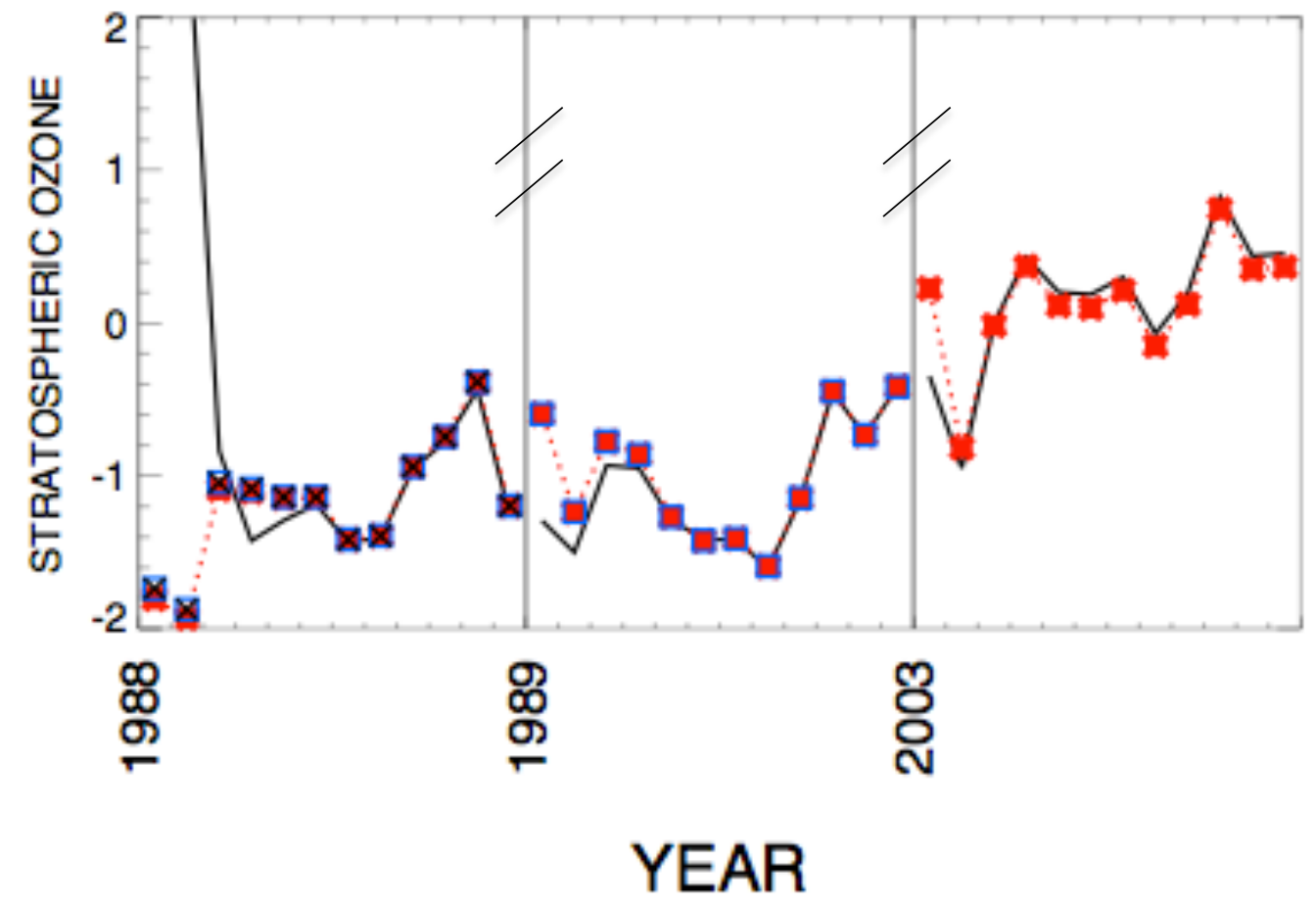


Figure S1: Monthly averaged simulated stratospheric ozone component north of $30-90^{\circ} \mathrm{N}$ and integrated below $300 \mathrm{hPa}$ for a series of 4 iterative simulations of the period 19881989, 3 iterative simulations of the period 1989-1990 and two iterative simulations of the period 2003-2004 (see text for details). Black line in each case gives the original and base simulation; dotted red line with red asterisks give the second simulation; blue boxes give the third simulation and crosses give the fourth simulation. The initial conditions for each simulation are taken as the final conditions from the previous simulation. In each case ozone is plotted as the monthly deviation (ppbv) from the 1995-2005 monthly mean, the base simulation period.

a)

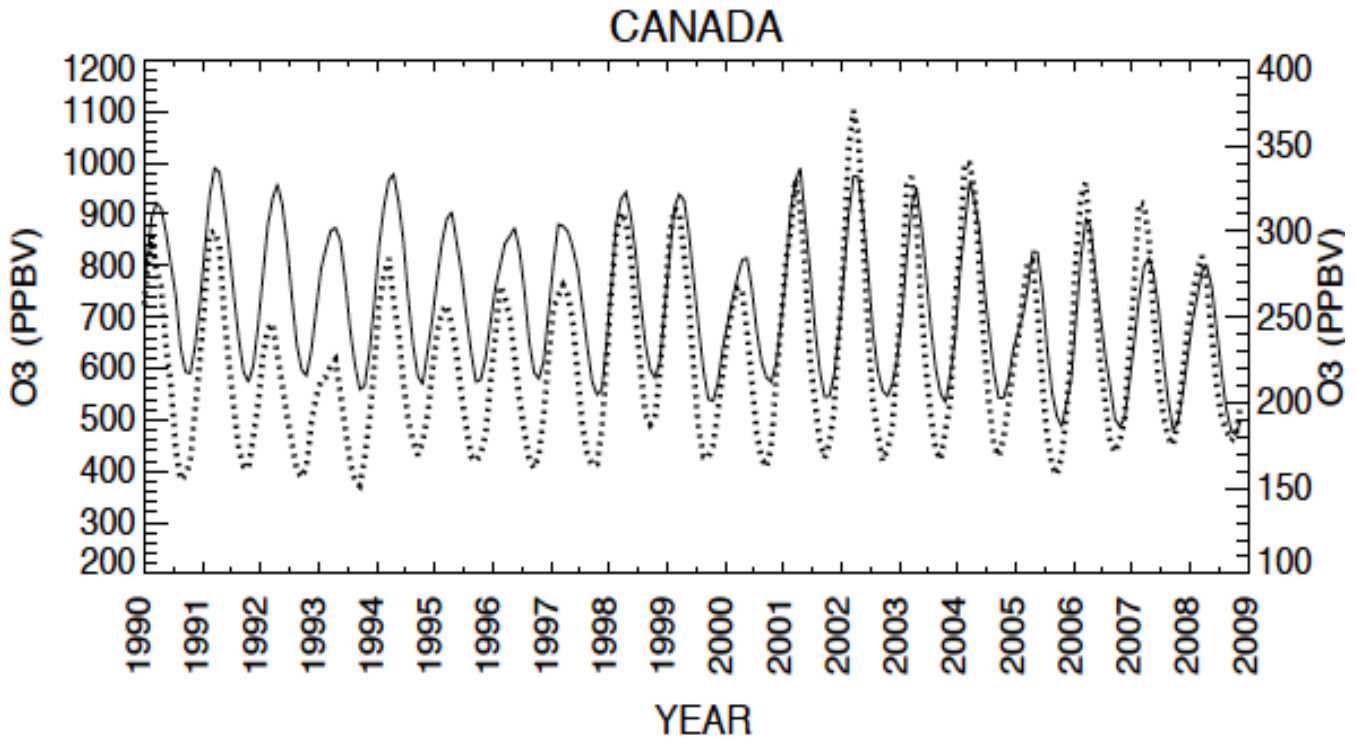

b)

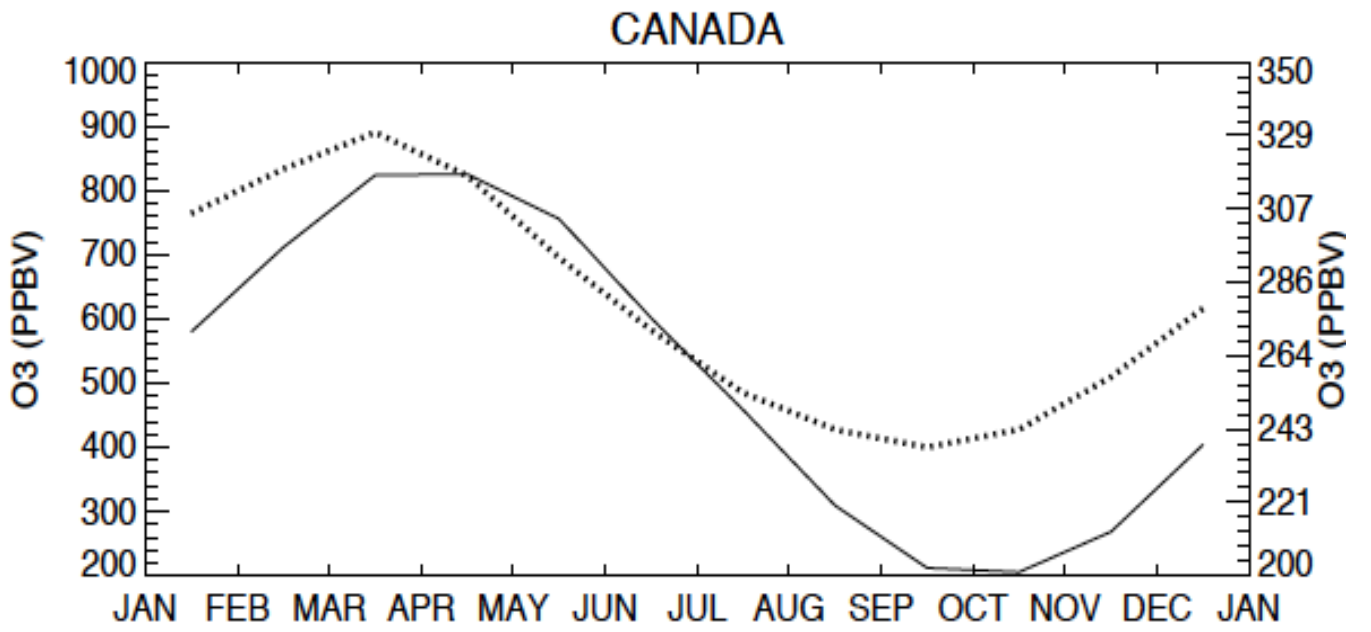


c)

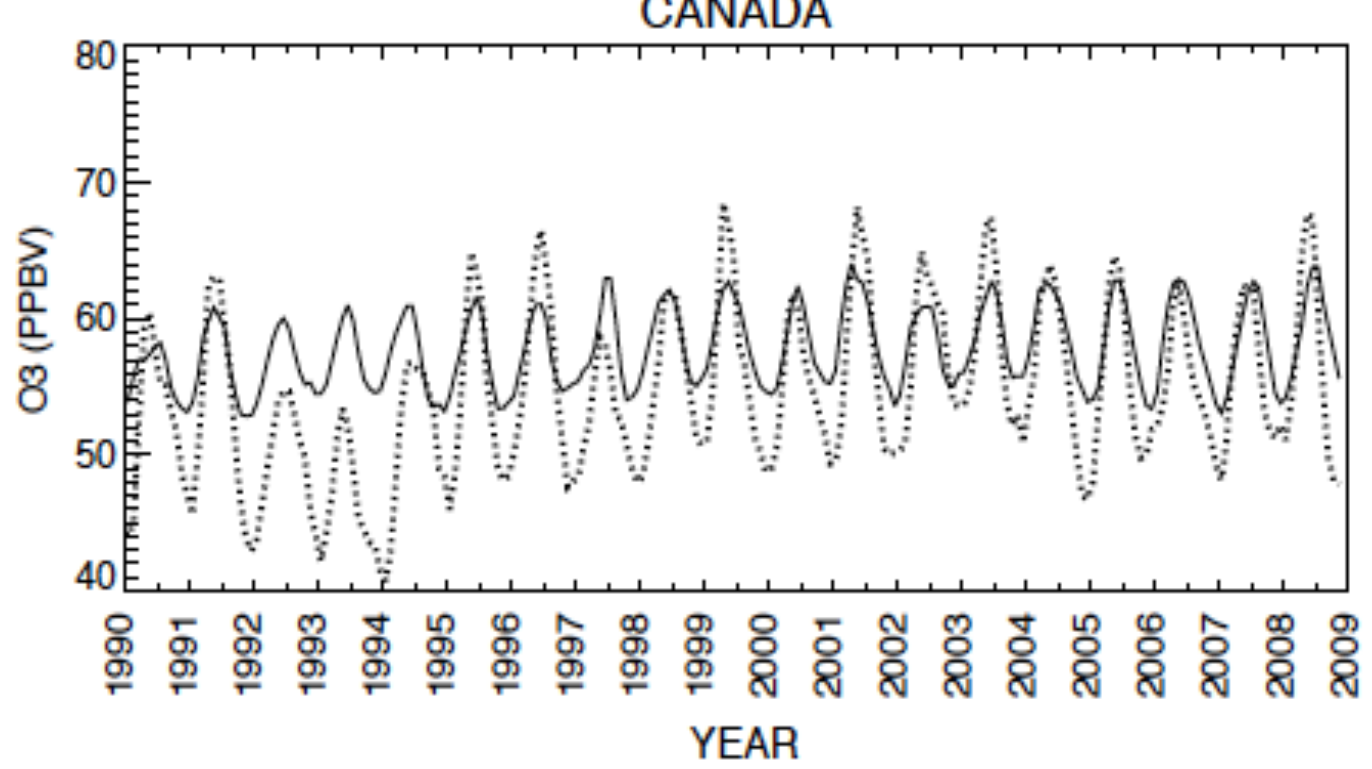

d)

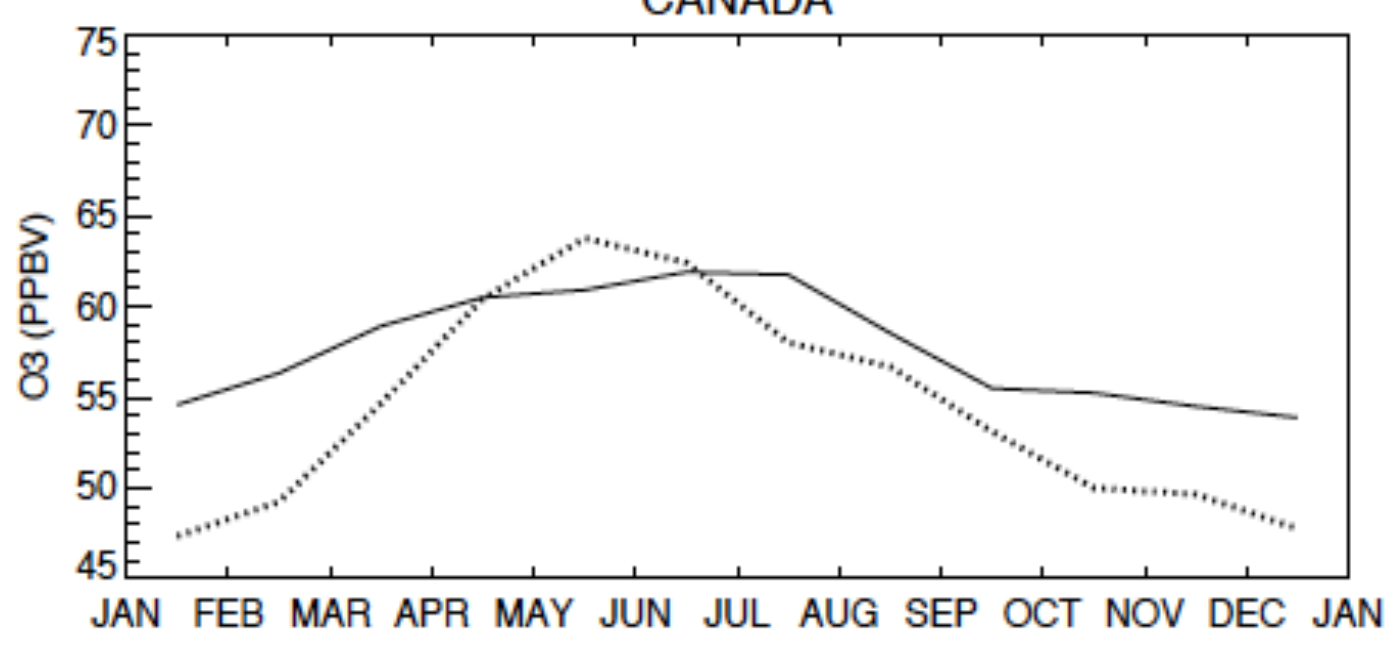

Figure S2. Simulated and measured ozone averaged over the six Canadian ozonesonde stations: a) Simulated (solid, left scale) and measured (dashed, right scale) ozone (ppbv) at $150 \mathrm{hPa}$; b) Average seasonal cycle of simulated (solid, left scale) and measured (dashed, right scale) ozone from (a), but with no smoothing applied; c) Simulated (solid, left scale) and measured (dashed, right scale) ozone (ppbv) at $500 \mathrm{hPa}$; d) Average seasonal cycle of simulated (solid, left scale) and measured (dashed, right scale) ozone from (c), but with no smoothing applied. 
a)



b)

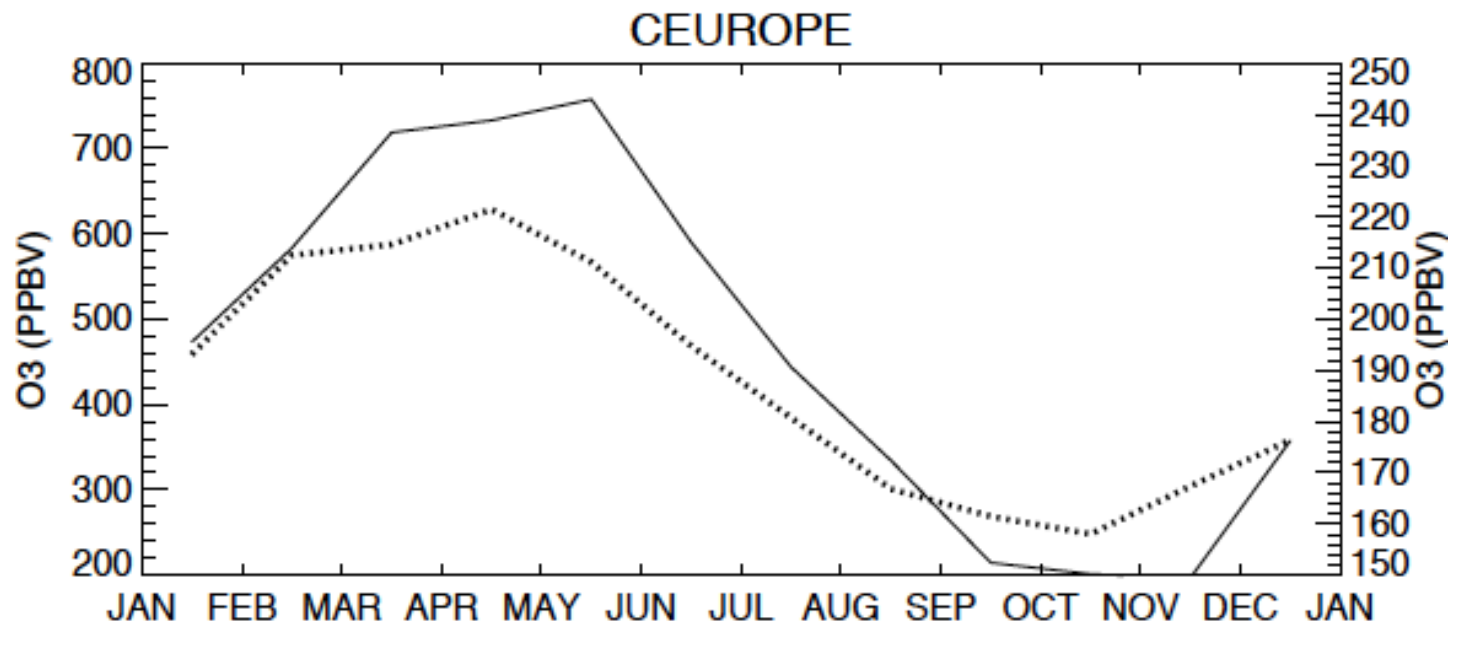


c)

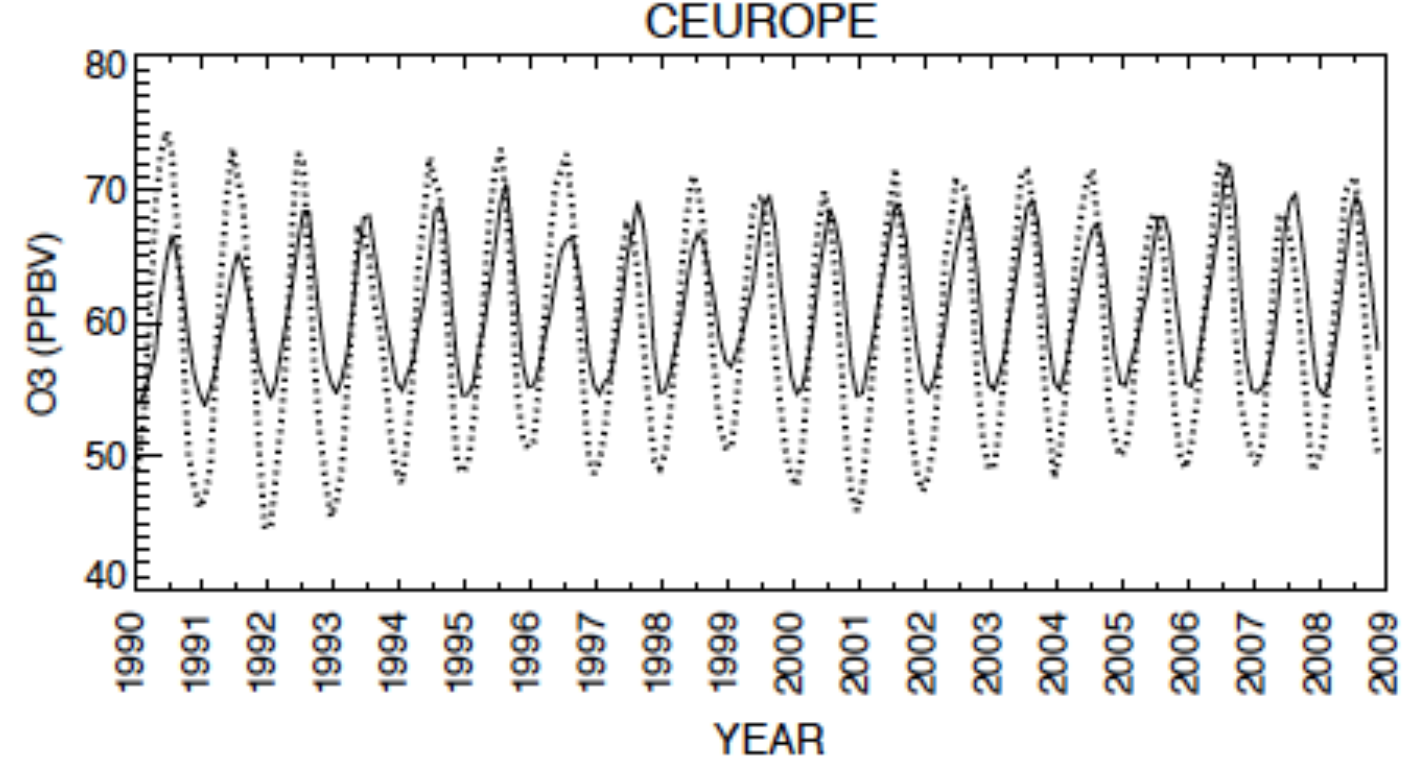

d)

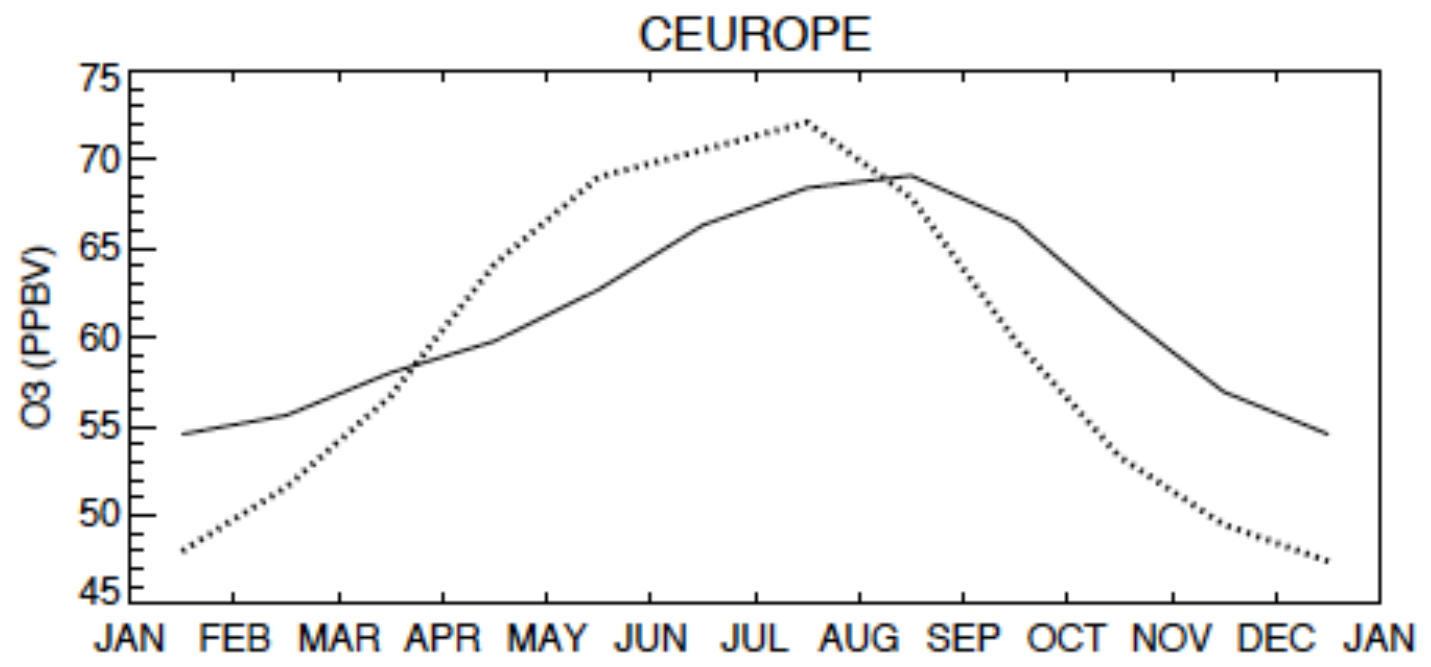

Figure S3. Simulated and measured ozone averaged over the five Central European ozonesonde stations and the $500 \mathrm{hPa}$ Central European MOZAIC cluster: a) Simulated (solid, left scale) and measured (dashed, right scale) ozone (ppbv) at $150 \mathrm{hPa}$; b) Average seasonal cycle of simulated (solid, left scale) and measured (dashed, right scale) ozone from (a), but with no smoothing applied; c) Simulated (solid, left scale) and measured (dashed, right scale) ozone (ppbv) at $500 \mathrm{hPa}$; d) Average seasonal cycle of simulated (solid, left scale) and measured (dashed, right scale) ozone from (c), but with no smoothing applied. 
a)

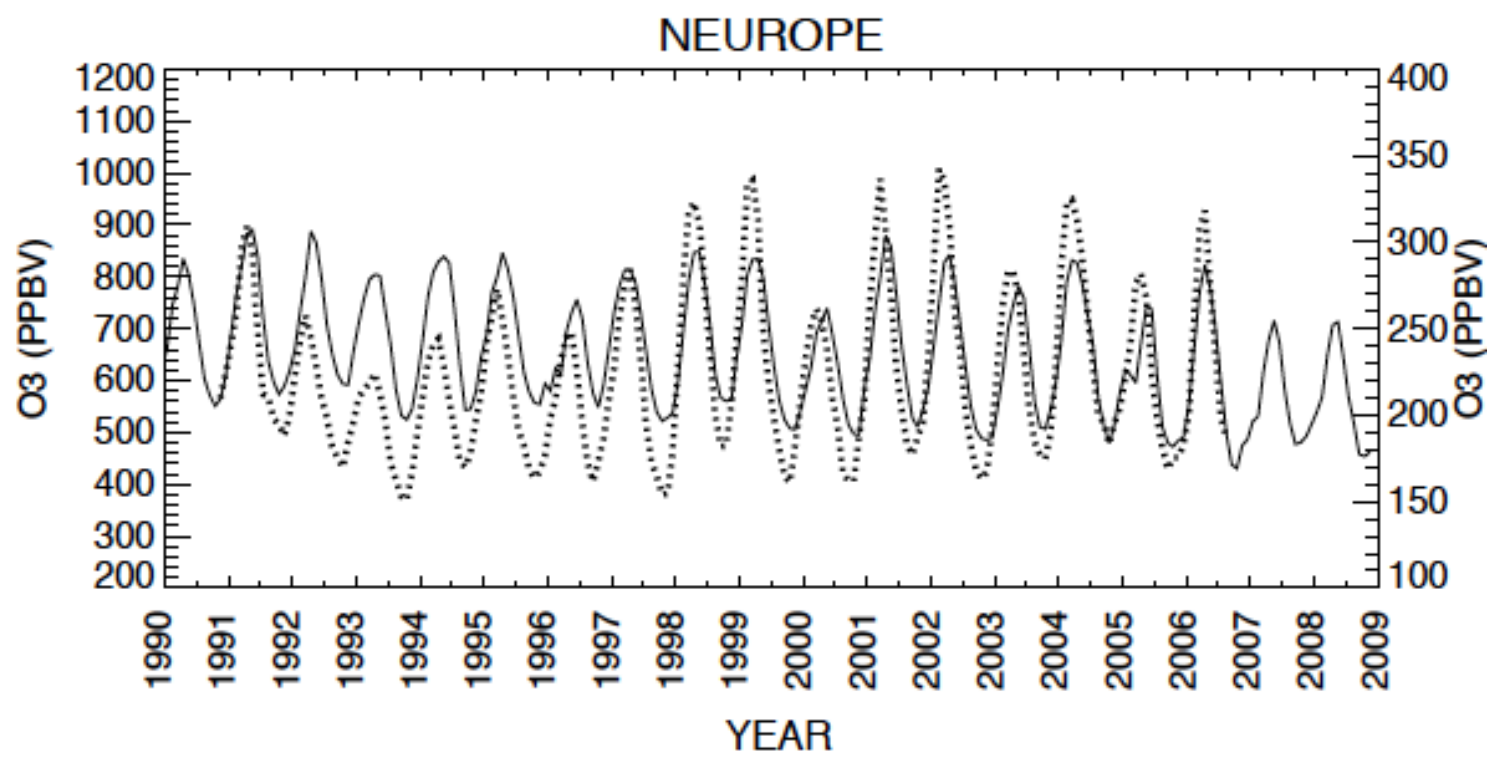

b)

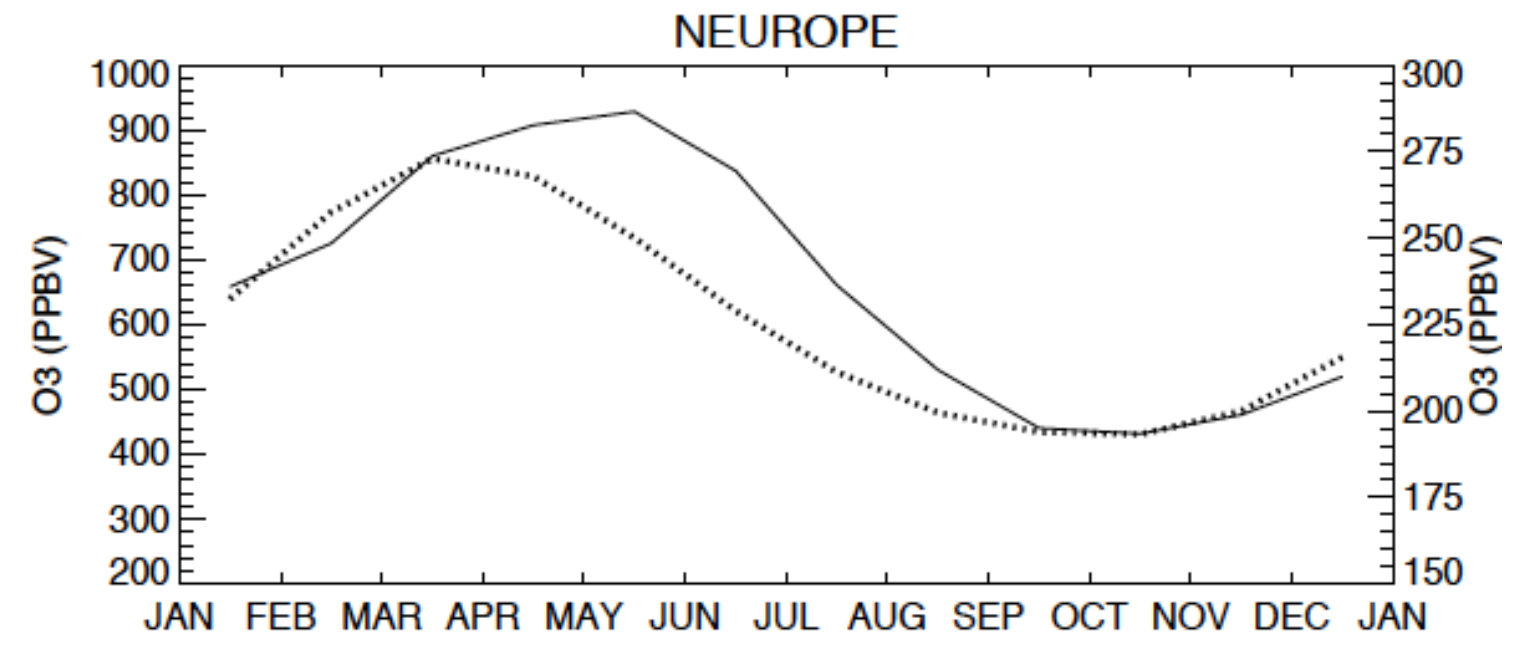


c)

NEUROPE

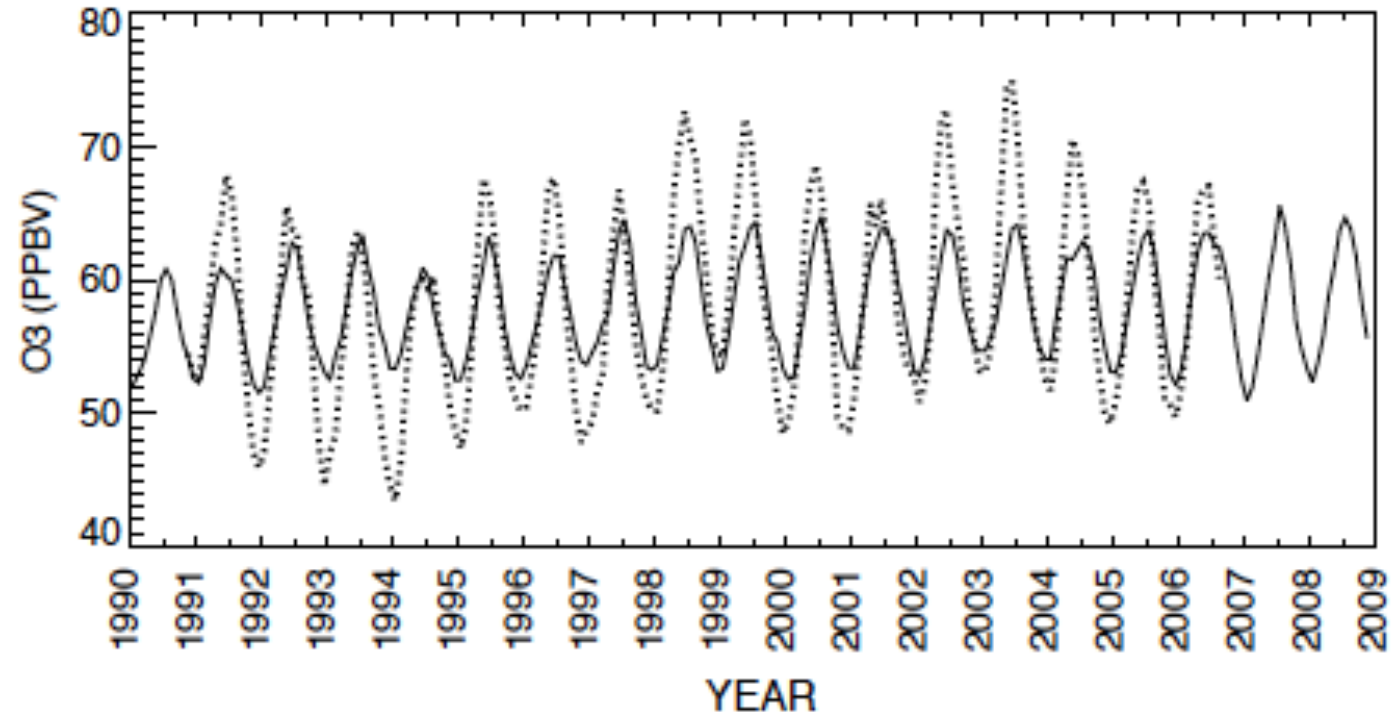

d)

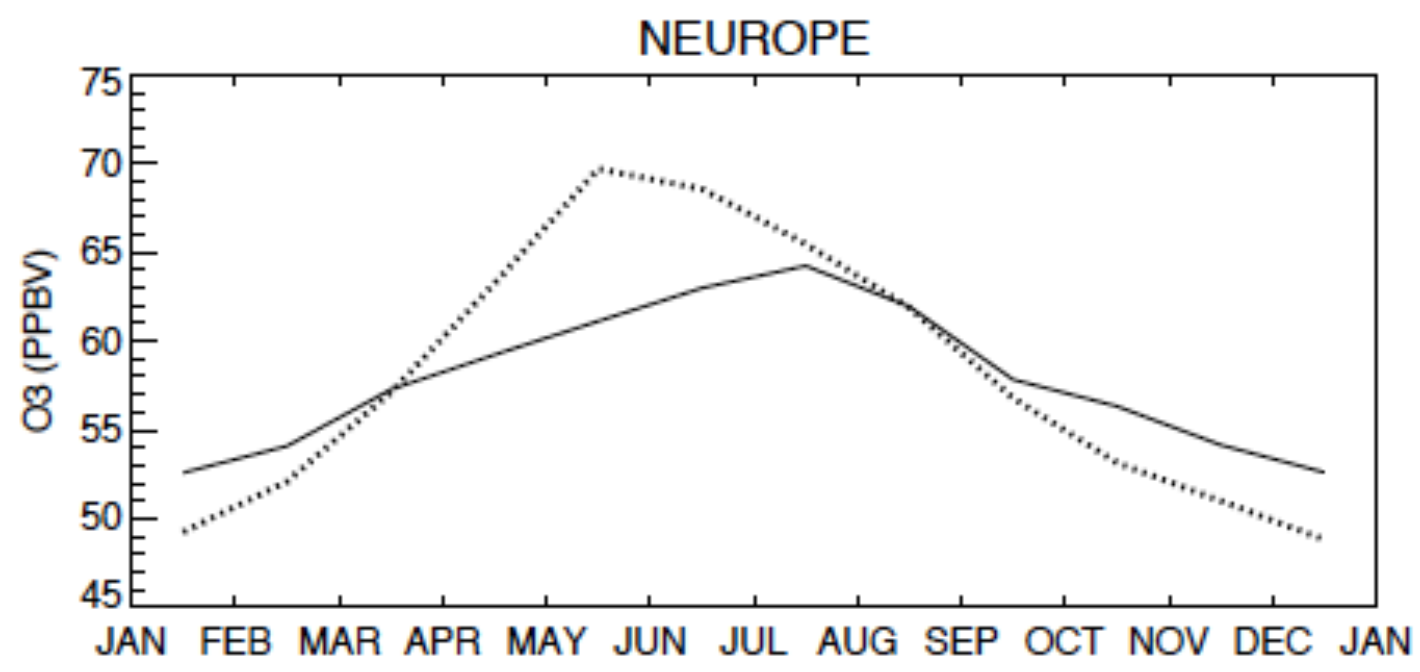

Figure S4. Simulated and measured ozone averaged over the three Northern Europena ozonesonde stations: a) Simulated (solid, left scale) and measured (dashed, right scale) ozone (ppbv) at $150 \mathrm{hPa}$; b) Average seasonal cycle of simulated (solid, left scale) and measured (dashed, right scale) ozone from (a), but with no smoothing applied; c) Simulated (solid, left scale) and measured (dashed, right scale) ozone (ppbv) at $500 \mathrm{hPa}$; d) Average seasonal cycle of simulated (solid, left scale) and measured (dashed, right scale) ozone from (c), but with no smoothing applied. 

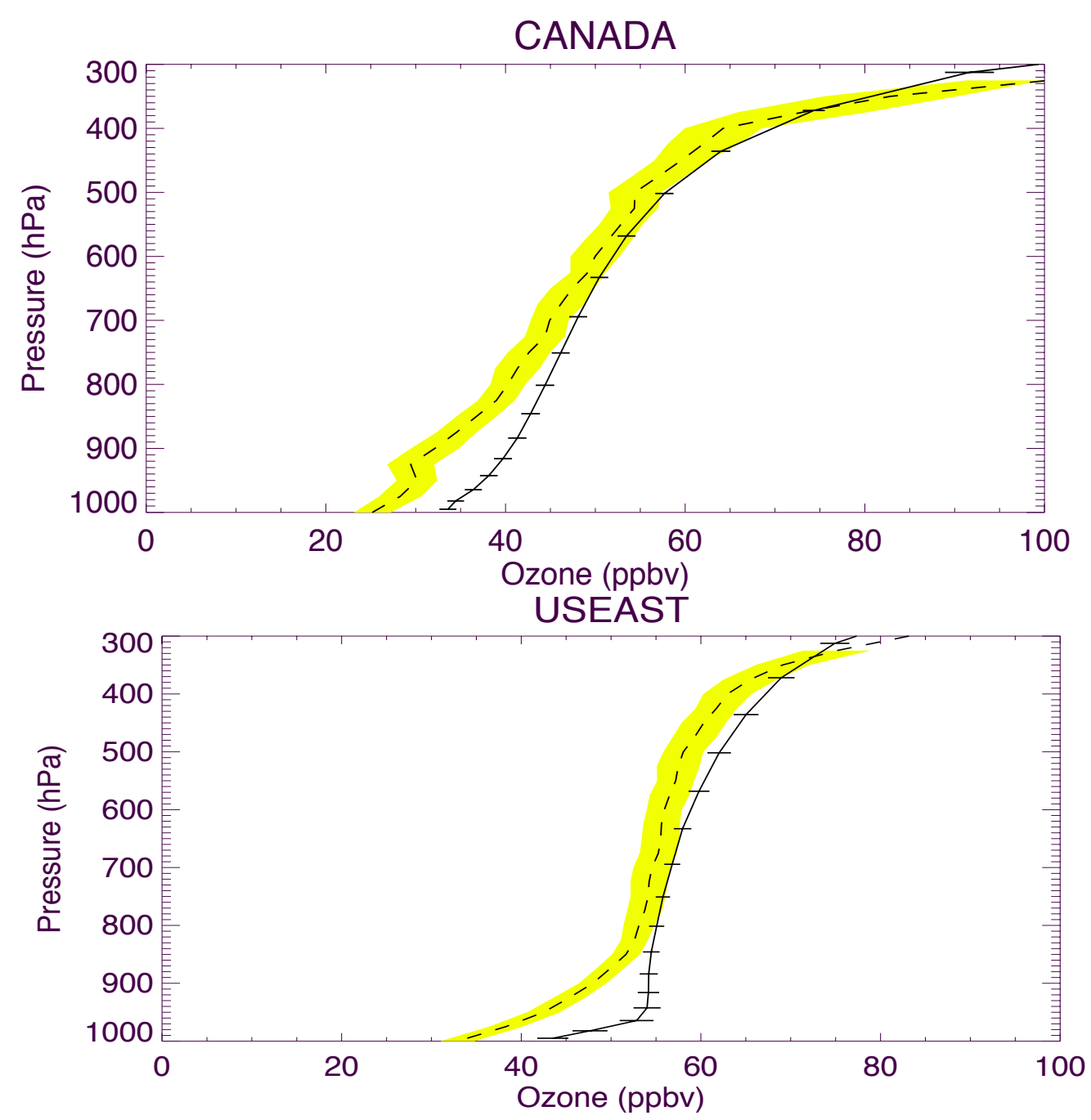

Figure S5. a) Average (1990-2009) simulated (solid) and measured (dashed) vertical profiles of ozone (ppbv) over a) the six Canadian ozonesonde stations and b) the Eastern US ozonesonde station and MOZAIC cluster. The standard deviation $( \pm \sigma)$ is given in yellow shading for the measurements and as horizontal lines for the simulation. The standard deviation is of the 12-month smoothed ozone record. 



Figure S6. a) Average (1990 -2009) simulated (solid) and measured (dashed) vertical profiles of ozone (ppbv) over a) the three Northern European ozonesonde stations and $b$ ) the over the five ozonesonde soundings and MOZAIC over Central Europe. The standard deviation $( \pm \sigma)$ is given in yellow shading for the measurements and as horizontal lines for the simulation. The standard deviation is of the 12-month smoothed ozone record. 


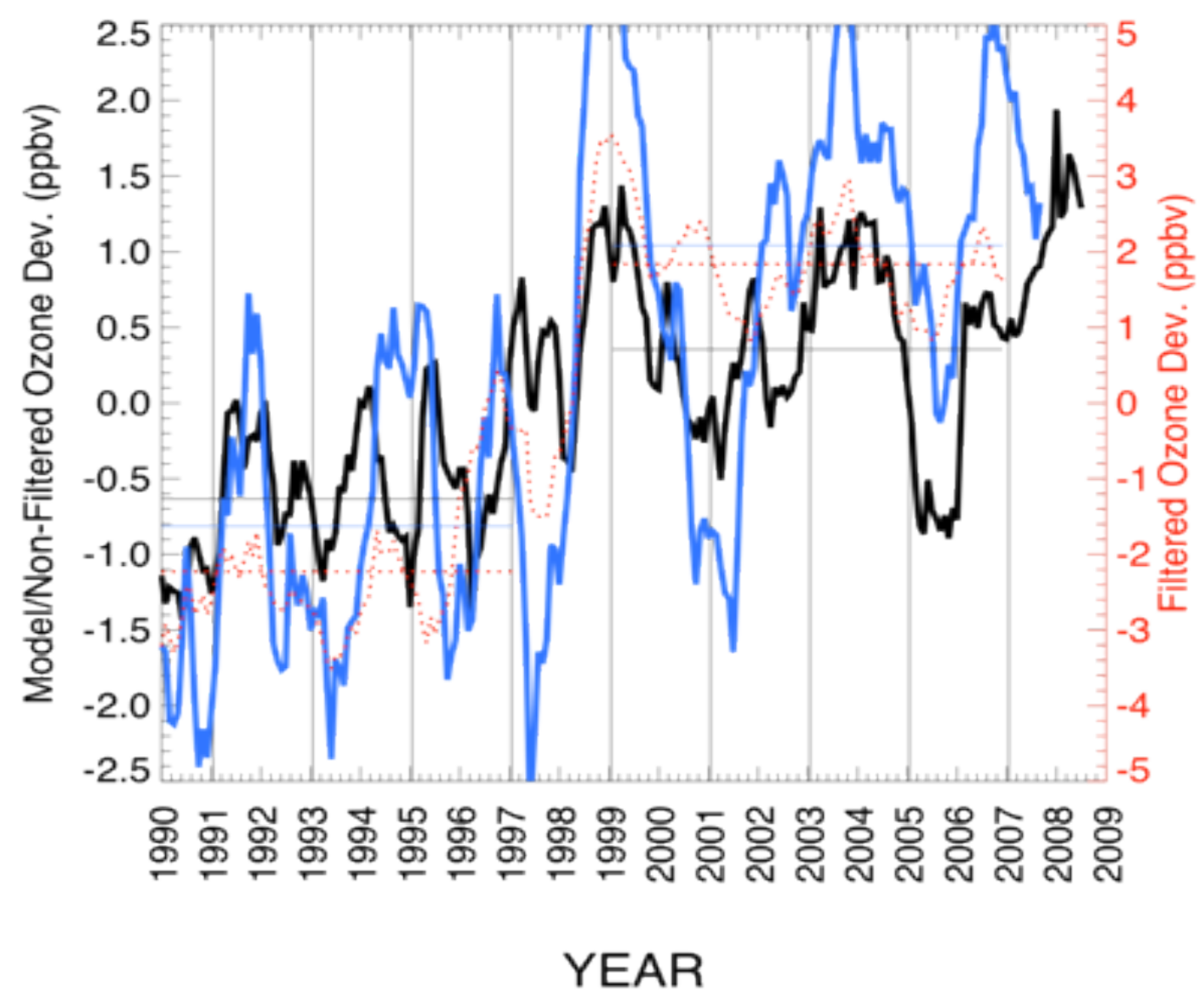

Figure S7: Measured and simulated ozone at Mace Head Ireland, where the S12MD ozone is plotted (ppbv). Simulated ozone (black), unfiltered measured ozone (blue) and filtered baseline measured ozone (red dotted) are shown. Scale for simulated and unfiltered measured ozone on left, for filtered measured ozone on the right. Horizontal lines give mean ozone values from 1989-1997, and from 1999-2007 for each of the ozone records. 

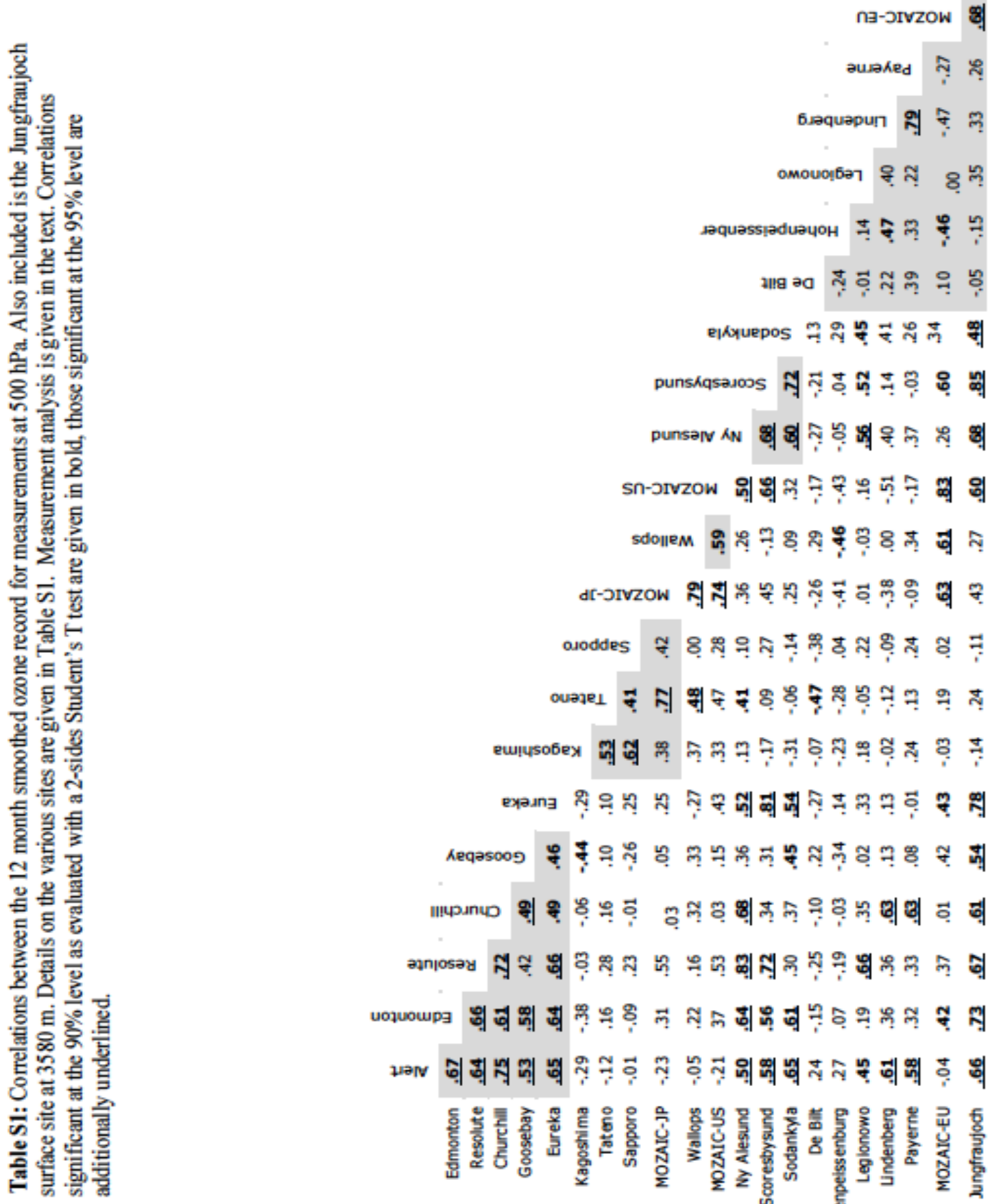

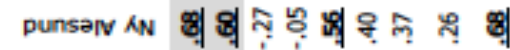

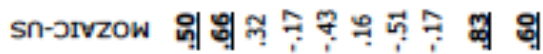

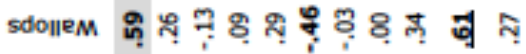

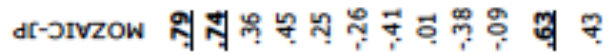

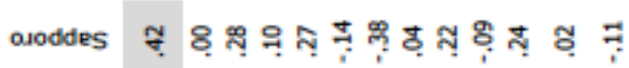

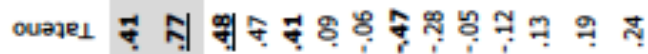

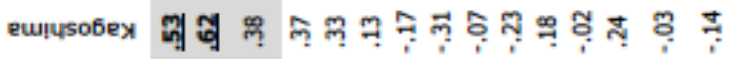

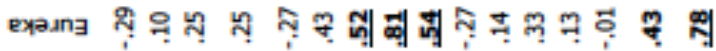

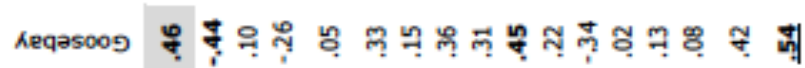

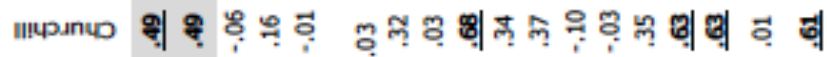

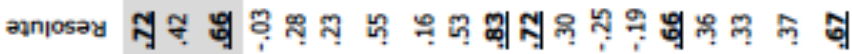

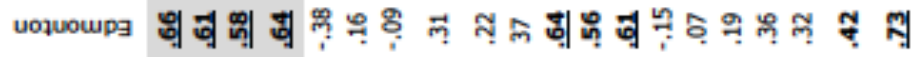

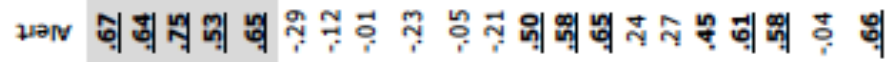

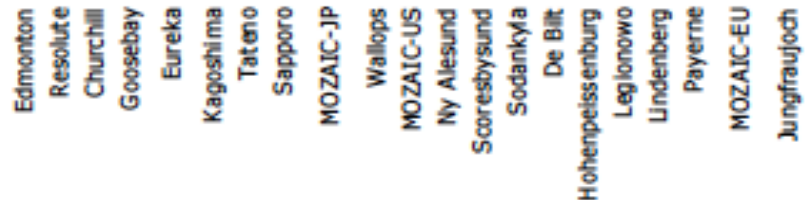



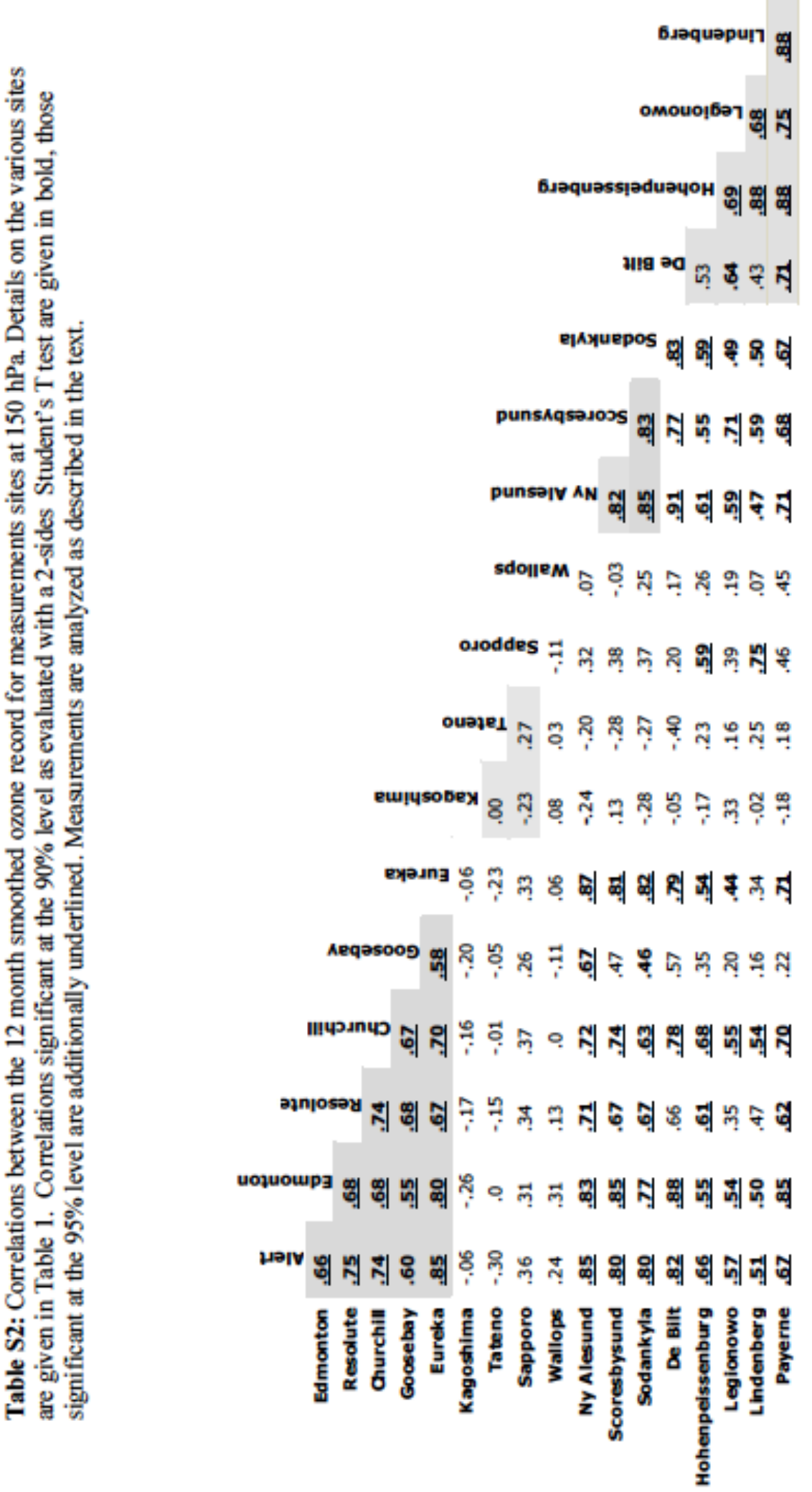
Table S3: Correlations between the 12 month smoothed ozone measured record at selected surface sites. Details on the various sites are given in Table S1.

Measurements are analyzed as described in the text. Correlations significant at the $90 \%$ level as evaluated with a 2 -sides Student's T test are given in bold, those significant at the $95 \%$ level are additionally underlined. Note that for the Mace Head site the baseline ozone data is used.

\begin{tabular}{|c|c|c|c|c|}
\hline & 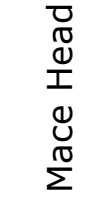 & $\begin{array}{l}\frac{t}{0} \\
\frac{0}{0} \\
\text { एँ }\end{array}$ & $\overline{\bar{\alpha}}$ & $\stackrel{\frac{1}{0}}{\stackrel{\partial}{\alpha}}$ \\
\hline Egbert & 0.39 & & & \\
\hline Rigi & 0.82 & 0.39 & & \\
\hline Ryori & 0.65 & 0.18 & 0.68 & \\
\hline JungfrauJoch & 0.83 & 0.52 & 0.88 & 0.78 \\
\hline
\end{tabular}

